・综述・

\title{
区域生命之树及其在植物区系研究中的应用
}

\author{
彭丹晓 ${ }^{1,2}$ 鲁丽敏 ${ }^{*}$ 陈之端 ${ }^{1}$ \\ 1 (中国科学院植物研究所系统与进化植物学国家重点实验室, 北京 100093) \\ 2 (中国科学院大学, 北京 100049)
}

\begin{abstract}
摘要: 区域生命之树是对一个区域内的所有物种进行生命之树重建, 在最近 10年已成为生命科学领域的研究热 点。生命之树反映了物种间的亲缘关系和进化信息, 可以将生物区系形成与发展过程中的进化和生态因素联系起 来，是揭示区系来源和演化规律的有效手段。本文从 3 个方面总结了区域生命之树在植物区系研究中的应用: (1) 在时间维度上，通过生命之树类群分化时间和进化速率估算，反映区系演化历史，揭示区系的时间分化格局; (2) 在空间维度上, 结合系统发育信息与物种分布数据, 揭示区系内生物多样性的空间格局, 并在此基础上进行区系 分区; (3)整合生物地理信息和气候环境数据，分析区系中生物类群对古地理事件以及气候变化的响应机制，以揭 示形成现存生物多样性格局的生态、地理和历史因素。此外, 我们阐述了区域生命之树与全球生命之树之间的关 系; 指出由于类群取样不全而造成的时间估算偏差是区域生命之树研究中需要注意的问题; 建议对生物多样性热 点地区从不同尺度进行大数据的整合分析。
\end{abstract}

关键词: 区域生命之树；植物区系；系统发育多样性；分化时间估计；时空格局；环境因子

\section{Regional tree of life and its application in floristic studies}

\author{
Danxiao Peng ${ }^{1,2}$, Limin Lu ${ }^{1 *}$, Zhiduan Chen ${ }^{1}$ \\ 1 State Key Laboratory of Systematic and Evolutionary Botany, Institute of Botany, Chinese Academy of Sciences, Beijing \\ 100093 \\ 2 University of Chinese Academy of Sciences, Beijing 100049
}

\begin{abstract}
The regional tree of life, reconstructing the tree of life to include the regional species pool, has been a research focus in biological science over the past decade. Informed by phylogenetic relationships among coexisting species, a regional tree of life can connect evolutionary and ecological factors during the evolution of a biota and thus has become an efficient tool to trace its temporal and spatial diversification. In this paper, we summarize the application of a regional tree of life in floristic studies in the following three fields: (1) To reveal temporal patterns of a flora by estimating divergence time and evolutionary rates based on the tree of life; (2) To reveal spatial patterns of the biodiversity in a flora and to guide the regionalization of floristic zones by integrating phylogenetic and spatial data; and (3) By integrating biogeographic and environmental data and investigating how taxa respond to paleogeographic events and thus climate change to reveal the underlying ecological, geographical and historic factors of the formation of the floristic biodiversity pattern. In addition, we highlight the relationship between the regional and global tree of life and indicate the potential to identify biased divergence times with incomplete taxa sampling using a regional tree of life. Finally, we suggest that future studies should integrate current mega data at different scales in hotspots to elucidate biodiversity patterns in a worldwide framework.
\end{abstract}

Key words: regional tree of life; flora; phylogenetic diversity; estimation of divergence time; temporal and spatial pattern; environmental factors

收稿日期: 2015-12-01; 接受日期: 2016-02-03

基金项目: 国家自然科学基金(31590822; 31500179; 31270268)、中国科学院国际合作局对外合作项目(GJHZ201321)、中非研究中心，中国科学院国际 合作和教育发展计划项目(SAJC201315)和科技部基础研究专项(2013FY112100)

* 通讯作者 Author for correspondence. E-mail: liminlu@ibcas.ac.cn 


\section{1 区域生命之树简介}

\section{1 区域生命之树的概念和研究内容}

达尔文在1859年就提出了生命之树(tree of life) 的概念, 他指出地球上的生命都是同源的, 任何生 物物种都是从一个共同祖先经过漫长的地质历史 逐渐演化而来。生命之树又称系统发育树 (phylogenetic tree), 是指地球上的生命之间的关联 和进化历史就像一棵树(鲁丽敏等, 2014), 分支表示 物种的分化, 节点表示延伸分支所代表物种的最近 共同祖先。生命之树不仅体现了生命的起源和生物 类群间的亲缘关系, 还能借以阐明生物的时空分布 格局和多样化进程。区域生命之树(regional tree of life)则是在空间范围上对取样类群进行限定, 构建 包含一个区域内所有物种的生命之树, 强调对特定 区域生物进化、历史地理过程及生物多样性地理分 布格局的研究。虽然生命之树的概念由来已久, 但 对一个区域内的物种进行生命之树重建, 并用于研 究该区系的生物多样性进化机制是在近 10 年才刚 刚兴起的(Webb et al, 2002)。

随着生物信息技术的快速发展、生物数据的大 量积累以及多学科交叉融合, 区域生命之树已成为 生命科学领域一个新的研究热点(Favre et al, 2015)。 区域生命之树的研究跨越了不同的空间尺度, 小至 生态群落, 大到生物区系。起初, 生命之树渗透到 群落生态学研究领域, 形成一门新兴的交叉学科, 称为群落系统发育学或系统发育群落生态学 (Phylogenetic Community Ecology)。这门学科以物 种生态位的系统发育保守性 (phylogenetic niche conservatism, PNC)为理论基础, 通过系统发育树所 反映的系统发育信息将进化和生态因素联系起来, 从而探讨物种共存和生物多样性的形成与维持机 制(Webb et al, 2002)。随后, 结合生命之树的生物区 系研究受到了广泛关注(Forest et al, 2007)。最近, Swenson和Umaña (2014)提出了系统发育区系学 (Phylofloristics)的概念, 即: 通过比较不同区系或 同一区系内不同区域间物种组成的系统发育相似 性, 探讨不同区系的生物是如何响应地质、生态因 子的变化而发生演替的。系统发育群落生态学和系 统发育区系学研究的空间尺度虽然不同, 但在研究 内容上部分重合, 群落水平的研究方法在经过物种 多度的简化、面积的标准化处理之后往往也能应用
于区系水平的研究(葛学军, 2015)。

建立区域生命之树, 可在时间维度上分析区域 内类群整体的时间分化格局，也可以在空间维度上 分析区域内类群整体的地理分布格局, 或是整合生 物地理信息和气候环境数据探讨区域生物多样化 格局形成的生态和进化因素。

\section{2 区域生命之树的特征量度}

在具体的研究中, 需要引入多种生物多样性量 度指标，才能对区系的分布格局及其形成机制进行 深入探讨。传统的物种丰富度(species richness)或分 类群多样性(taxonomic diversity, TD)以物种数目为 量度单位, 一直是生物多样性最基本的衡量指标。 自区域生命之树应用于生物区系研究以来, 结合生 命之树的多样性量度及其应用受到特别关注。Faith (1992)提出的系统发育多样性 (phylogenetic diversity，PD)指标得到了广泛应用，该指标以系统发育 树上符合最小距离路径(minimum spanning path)的 分支的枝长(也可以是时间估算树的分化时间)总和 来表示。有些研究通过计算和对比物种丰富度和系 统发育多样性, 已经证明物种丰富度和系统发育多 样性之间并不一定正相关。例如, Forest等(2007)重 建了南非好望角735属本土特有物种的生命之树, 发现PD值所指示的生物多样性区域与通过物种丰 富度估计的区域并不吻合, 物种丰富度不具优势的 好望角东部地区反而具有更高的系统发育多样性, 在生物多样性保护方面具有更大的价值, 但在之前 实施的生物多样性保护策略中这些地区常常被忽 视。因此, 在分析区域的生物多样性格局和制定保 护策略时要综合考虑物种丰富度和系统发育多样 性, 以全面揭示生态和进化因素在生物多样化进程 中扮演的角色。此外, 近年来基于物种功能特征的 功能多样性(functional diversity, FD)在生态学领域 也备受重视。功能性状是指可以影响生态系统属性 或生物对环境变化产生应答的性状, 是理解生态系 统多样化进程及其对环境胁迫和干扰响应的重要 途径(Chao et al, 2014)。功能多样性可通过3种方法 量度: 基于性状值(trait-value based)、基于系统发育 树图(dendrogram based)和基于物种功能属性距离 (distance-based)。目前, 功能多样性与系统发育多样 性和物种丰富度之间的相关性还没有定论, 但已成 为进化生态学研究关注的热点之一。Corbelli等 (2015)对比了新热带南部4种群落(亚热带森林、草 
原、造林区和农田)中的指示生物鸟类和蚂蚁的物种 丰富度、系统发育多样性和功能多样性, 结果显示 三者呈正相关, 且群落类型和用地情况对 3 种多样 性指标影响显著。而Monnet等(2014)研究了法国鸟 类的物种丰富度、系统发育多样性和功能多样性在 过去20年的动态变化, 结果显示物种丰富度和系统 发育多样性在此期间有显著增加, 而功能多样性并 无明显变化。该研究显示不同层面的多样性指数之 间的不同步性。因此, 建议在宏观生态学研究中采 用尽可能多的指数以更好地理解群落组成的变化。

Chao等(2014)还提出了属性多样性(attribute diversity)的概念, 将分类群实体(物种)、系统发育实体 (单位长度的分支)或功能实体(单位距离的物种对) 看作有效物种数量(Hill numbers, effective number of species)中的“物种”进行度量，作为量化物种多 样性、系统发育多样性和功能多样性的综合方法。

近年来, 随着生命之树在植物区系研究中的广 泛应用, 系统发育多样性的概念不断丰富和发展, 除了Faith (1992)的计算方法, 各种具体的量化指标 也陆续被提出。Whittaker (1960)指出, 一个区域的 生物多样性 ( $\gamma$ 多样性) 是由该区域局部生境的平均 生物多样性( $\alpha$ 多样性)和这些生境之间的多样性差 异( $\beta$ 多样性)所决定的。在生命之树引入生物多样性 研究后, 区域生物系统发育多样性也可以分解为系 统发育 $\alpha$ 多样性和系统发育 $\beta$ 多样性(González-Caro et al, 2014)。Feng等(2012)以浙江古田山的森林群落 样地为例, 对 8 种系统发育 $\beta$ 多样性指数进行了比较 和相关性分析, 结果显示不同指数对不同空间尺度 的物种空间分布差异的解释能力不同, 且意义相近 的指数之间相关性较高。因此, 在利用系统发育多 样性指标对生物多样性进行量化时, 要在理解其生 态学意义的基础上根据具体情况选择合适的指标, 以准确合理地反映区域的生物多样性。

除了系统发育多样性, 对区域生命之树的其他 特征的度量也受到关注。如: 分类单元间平均谱系 距离(mean pairwise phylogenetic distance, MPD)反 映了系统发育树的分支结构特点, 距离越大表示分 支越发散(overdispersed), 类群间亲缘关系较远; 距 离越小表示分支越聚集(clustered), 类群间亲缘关 系较近(Tsirogiannis \& Sandel, 2014)。Faith等(2004) 和 Rosauer等(2009) 分别建立了系统发育特有性 (phylogenetic endemism, PE) 指数的概念。Mishler等
(2014)认为Faith等(2004)的方法旨在鉴别系统发育 树上局限分布于某个特定区域的类群(特有属、特有 种等), 可称为绝对系统发育特有性(absolute phylogenetic endemism); 而Rosauer等(2009)考虑了特 有类群地理分布的相对幅度, 称为加权的系统发育 特有性(weighted phylogenetic endemism)。在考虑分 支的长短、发散或聚集程度的基础上, Mishler等 (2014)提出相对系统发育多样性(relative phylogenetic diversity, RPD)和相对系统发育特有性(relative phylogenetic endemism, RPE)的概念, 以此区别类 群的新特有和古特有性质, 并根据特有属、种的 数目和比例来判断一个地区是新特有还是古特有 中心。

\section{2 区域生命之树在植物区系研究中的应用}

\section{1 植物区系的生物多样性时间格局}

植物区系是一个地区所有植物的总和, 是植物 界在一定自然历史环境中时空分布和演化的综合 反映。它既反映了一个区域中植物和环境的因果关 系, 还反映了植物区系的自然历史演化脉络(吴征 镒等, 2010)。系统发育树除了可以直观地呈现植物 区系中的类群组成及类群间的亲缘关系外，还可以 通过时间标定提供区系中各类群的分化时间, 从而 分析不同地质历史时期科、属、种的丰富度和关键 创新性状(key innovations), 并回答在哪个地史时期 发生了物种快速分化以及区系生物多样性形成和 发展的驱动力等科学问题。因此, 系统发育树成为 揭示植物区系生物多样性时间格局的有效手段。

具有时间标定的系统发育树(时间树)可以标识 不同生物类群的分化时间和进化速率，而对区系群 落中优势种、特征种或指示种分化时间的估算则能 够帮助确定该区域典型植被形成的时间和过程，进 而指示区系生物多样化过程中的重大地史事件和 环境变迁。Pillon (2012)利用时间树对新喀里多尼亚 区系多样化的时间和速率进行估算, 结果表明所研 究的 12 个植物类群都是在 $37 \mathrm{Myr}$ 之后才散布至该 地区并分化，对应于该岛从澳洲大陆分裂后曾经被 洪水淹没的时间，由此推测新喀里多尼亚区系是在 该岛经历过这次洪水后重新出现时才形成的; 又以 热带雨林特有类群的冠群年龄(crown age)估算该岛 雨林出现的时间, 表明该岛的热带雨林生境至少存 在了6.9 Myr。 
物种快速分化可以导致植物区系的生物多样 性增加, 而分化时间和速率的不同则呈现出不同的 物种多样化格局。高的物种丰富度可能由低灭绝率 (保存了“早期的物种辐射”的物种多样性)或者“近 期的快速物种辐射” 导致。Linder (2008)对不同植物 区系(安第斯山脉、新西兰、澳大利亚、非洲西南部、 热带和欧亚大陆)时间标定类群分支的物种形成和 灭绝的速率进行非线性回归分析, 结果表明: 澳大 利亚的生物多样性是“早期物种辐射”遗留下来的, 以新近纪气候和地理条件稳定为特点; 新西兰植物 区系是“近期的快速物种辐射”的结果, 具有典型的 上新世新生环境; 新热带和好望角植物区系的高物 种多样性则是“早期物种辐射”和“近期的快速物种 辐射” 共同作用的结果, 兼具稳定的环境(亚马逊盆 地和Cape Fold Mountain)和不稳定的环境(地壳运 动比较活跃的安第斯山脉和南非西海岸)。

区系中类群的分化规律及散布过程反映了区 系生物多样性的时间格局和区系的形成历史。Crisp 和Cook (2013)综述了澳大利亚区系从冈瓦纳古陆 分离后转变为如今的岛屿大陆过程中发生的主要 进化和生态过程, 强调了具有时间标定的系统发育 树对于阐明澳大利亚区系历史和演化机制的重要 性。该研究通过对比 85 个维管植物分支的分化时间, 发现 38 个分支(45\%) 可能起源于冈瓦纳古陆, 41 个 分支 $(48 \%)$ 可能通过远距离散布到达澳大利亚。又 通过对比在澳大利亚和其他大陆间断分布类群的 分化时间, 发现只有南美一澳大利亚间断表现出了 明显的隔离分化(vacariance)特征, 因为 21 个样本的 分化时间中值为 $33 \mathrm{Myr}$, 与两个大陆分离的时间相 吻合。结合时间标定的系统发育分析还支持了澳大 利亚温带区系起源于冈瓦纳古陆、热带类群是由亚 洲扩散而来的假说。

\section{2 植物区系的生物多样性空间格局}

以植物区系物种分布信息和系统发育树为基 础, 通过比较地区间的物种丰富度、系统发育多样 性及其变化, 即对生物多样性空间格局进行横向比 较( $\beta$ 多样性)和关联分析, 可以阐明区系物种的空间 分布格局及其形成机制。Weigelt等(2015)对世界范 围内的393个岛屿区系的物种分布格局进行分析, 比较了各个岛屿的被子植物、棕榈类和痥类植物的 物种丰富度、系统发育多样性和结构, 并与地质历 史、环境因子和岛屿特征等关联, 分析类群组成、
远距离扩散、环境过滤和原地物种形成对现存分布 格局的作用。结果表明, 相比于偋类植物, 物理和 环境因子(特别是与定殖和远距离扩散相关的)能够 更好地解释被子植物和棕榈类植物的分布规律, 说 明不同植物类群具有不同的扩散能力、物种形成相 关特征和对环境的适应性，同一区系中不同植物类 群的多样性格局只有在充分考虑各自散布机制的 情况下才能进行合理的解释。

植物区系区划是在区域现存的生物多样性空 间格局的基础上，综合地质历史、生物地理、气候 变化等各种因素, 将各个地域划分为具有生物时空 分布特征的不同区域(吴征镒等, 2010; Li et al, 2015)。传统植物区系区划以植物类群的分布状况及 其在该区域的特有性程度为基础, 主要以物种丰富 度和物种特有性为量度指标 (吴征镒等, 2010)。利用 区域生命之树, 基于其所反映的系统发育信息和系 统发育多样性等指标对植物区系进行系统发育地 理分区, 则可以把具有相同生态和进化历史的区域 划分在一起, 能更清晰地反映不同植物区系单元的 演化历史和生物多样性空间格局。如 $\mathrm{Li}$ 等(2015)利 用云南地区种子植物的 1,983 个属的分布和系统发 育关系信息, 提出云南植物区系分区系统, 将云南 地区划为南北两个地理单元, 其下再分为 8 个不同 的植物区系, 与此前基于木本植物分布定性分析的 区系划分结果大抵一致; 并以 $\beta$ 多样性为量度探讨 了云南区系形成过程中物种丰富度和系统发育多 样性的转换(turnover)格局, 发现这两者高度相关, 且均在中部地区表现为最低水平。

\section{3 植物区系生物多样性时空格局的地理、生态因 子解释}

植物区系的生态环境分异是物种多样化的外 因, 而生物类群通过进化创新以适应环境变化是物 种多样化的内因, 可以通过系统发育树的结构得到 反映。因此，在揭示区系时间和空间格局的基础上, 系统发育树还可以将外界环境因子和关键适应性 特征进化相联系, 即结合物种分化的外因和内因, 从而理解区系生物多样性的形成机制和动态变化 规律(鲁丽敏等, 2014)。Lavergne等(2013)基于区域 生命之树, 通过birth-death模型对物种多样化速率 进行分析, 探讨了直布罗陀海峡对两岸植物区系生 物多样性格局形成的影响。结果表明, 陆桥对大陆 间的物种迁移有影响, 通过生活史特征的选择对类 
群进行迁移过滤，使得生活周期短、借助风或动物 传播的类群不成比例地分布于海峡两岸。此外, 海 峡对迁移的限制还使一些类群倾向于本地物种形 成的多样化模式, 在多样化速率相当的情况下, 由 于生境差异而产生了两岸大量的地方特有种。

大数据的整合分析是研究植物与环境相互影 响的重要方向。特别是区域时间树引入植物区系的 研究后, 进化生态学家常常将系统发育关系、分化 时间、多样化速率、生物地理重建和古气候数据进 行关联分析, 用以揭示区系生物多样化对地理、地 质事件和气候变化的响应机制。Warren等(2011)基 于系统发育树和过去几百万年的季节性降雨的变 化数据, 重建了好望角植物区系物种地理分布和开 花物候的历史变化。结果显示, 分别有 $14-41 \%$ 和 $14-55 \%$ 的物种符合预测适应气候变化的地理分布 和开花物候转变, 指出中新世以来的气候变化对好 望角现存植物区系生物多样性格局的形成有显著 影响。

\section{3 存在问题与前景展望}

\section{1 区域生命之树和全球生命之树之间的关系}

区域生命之树是全球生命之树在区域范围的 取样, 仅反映了在某个特定区域内的系统发育多样 化格局。取样不全造成生命之树上分支缺失会影响 对系统发育关系的判断, 并造成全球树与区域树所 反映的系统发育多样性的差异。但这两者反映的系 统发育关系之间的误差是否会影响讨论生物多样 性格局及其成因, 目前的研究还少有涉及。以 Weigelt等(2015)的工作为例, 其研究用综合的全球 岛屿区域树的系统发育数据与地理环境等因素进 行分析, 得到两者相关性显著的结果, 由此揭示了 世界范围适用的岛屿区系生物多样性格局形成模 式。而在此基础上，可以通过合并所有岛屿区域树 构建全球尺度的岛屿树, 进一步比较岛屿的全球树 和全球的岛屿树得到的多样化成因是否存在差异, 为揭示全球生命之树和区域生命之树的关系提供 参考。另一方面，区域生命之树由于取样不全而可 能造成的系统发育关系分析误差也可以通过与完 整呈现生物类群间系统发育关系的全球生命之树 比对来进行修正。

\section{2 区域生命之树的时间估计偏差}

分子时间标定是确定一个物种分化事件发生
时间的过程。首先，利用DNA序列构建系统发育树， 以序列的碱基替换数来衡量分支长度; 然后，由于 类群间的碱基替换率不同而不能直接将分支长度 转化为估计的分化时间，所以第二步是将分支的碱 基替换数转化为相对时间的度量(rate-smoothing); 第三步是用化石进行校准, 将相对时间转化为实际 时间(Milne, 2006)。不同类群中包含的物种数量差 异很大，系统发育树的类群取样数目会影响时间估 计的准确性(Linder et al, 2005), 而且不同的估算方 法可能会产生不同的节点时间。区域生命之树的类 群取样仅限于区域分布的物种, 必然存在由于取样 不全而造成对类群间亲缘关系和类群分化时间估 计的精度降低的问题。此外, 由于所取类群受限而 化石记录有限，因此有可能出现所建的区域树的部 分分支缺少化石校准数据(Lancaster \& Kay, 2013), 从而产生时间估算误差。Milne (2006)建议利用多个 化石记录和多个基因序列来减小碱基替换率随机 变异的影响, 以此建立一个普遍适用的时间估算方 法，使准确的时间标定不再局限于化石记录丰富的 类群。同时，区域时间树存在的偏差是否可以采用 区域时间树与区系内特征类群在世界范围取样所 构建的时间树相互验证的方法进行校正? 是否可 以通过建立一个整合世界范围生物类群估算分化 时间的数据库以便于数据的提取、比对和修订, 再 基于此数据库对区域生命之树进行时间标定? 这 些都是特别值得关注的问题。因此，探索区域生命 之树时间的估算方法以解决由于取样不全而造成 的误差, 将成为今后研究的一个重要方面。

\section{3 取样尺度的影响}

区域生命之树在系统与进化生物学和生态学 之间架起了桥梁, 已经广泛应用于揭示区系生物多 样性的时间和空间格局及其地理、生态成因，而在 研究过程中取样尺度大小对结果的影响也是未来 研究应该关注的方面。在时间尺度上，比较同一地 区在不同时间跨度的物种丰富度和系统发育多样 性的变化规律, 阐明地质历史和气候变化对多样化 的作用强度和快慢; 在空间尺度上，比较不同空间 大小的地区在某个历史时期的多样化规律，探讨空 间取样大小造成的分析结果差异及原因; 系统发育 树建树的取样量和分类阶元水平也可能会影响到 分析结果。Qian和Zhang (2015)利用北美被子植物木 本类群在科水平的系统发育树和物种水平的系统 
发育树研究系统发育多样性与环境变量之间的关 系, 发现两种水平上的树得到的关系没有显著差 异, 表明高分辨率的科水平树在较大空间尺度上也 能很好地反映环境因素对多样性格局的影响。但不 同时间、空间尺度和不同分类阶元水平上建树尺度 的组合得到的分析结果是否存在差异仍有待进一 步研究。

\section{4 对生物多样性热点地区研究成果的整合}

生命之树已广泛应用于植物区系研究, 尤其是 生物多样性热点地区受到研究者的格外关注, 并积 累了一定的研究成果。但对同一地区的研究往往各 有侧重, 不同指标、模型和方法被用于解读和挖掘 系统发育树中的信息, 再结合不同的进化特征、生 物地理分析和地质气候数据进行分析, 得到了从不 同角度对同一地区生物多样性起源演化的理解, 因 而加强世界范围内研究者的合作与交流很有必要。 今后的研究除了对尚未涉猎的植物区系结合区域 生命之树进行探讨, 或是继续从新的方面加深对已 有研究涉及的地区的多样化机制的认识之外, 整合 热点地区的研究以进行全方位、多角度、深层次的 大数据整合分析, 进而完整地阐明生物多样性热点 地区生物多样性格局及其成因可能会成为今后重 点研究方向。这将为最终解释全球生物多样性的形 成机制和分布规律奠定基础。

致谢: 感谢中国科学院植物研究所胡海花博士对原 稿提出修改意见并提供文献。

\section{参考文献}

Chao A, Chiu CH, Jost L (2014) Unifying species diversity, phylogenetic diversity, functional diversity, and related similarity and differentiation measures through Hill numbers. Annual Review of Ecology, Evolution, and Systematics, 45, 297-324.

Corbelli JM, Zurita GA, Filloy J, Galvis JP, Vespa NI, Bellocq I (2015) Integrating taxonomic, functional and phylogenetic beta diversities: interactive effects with the biome and land use across taxa. PLoS ONE, 10, e0126854.

Crisp MD, Cook LG (2013) How was the Australian flora assembled over the last 65 million years? A molecular phylogenetic perspective. Annual Review of Ecology, Evolution, and Systematics, 44, 303-324.

Faith DP (1992) Conservation evaluation and phylogenetic diversity. Biological Conservation, 61, 1-10.

Faith DP, Reid CAM, Hunter J (2004) Integrating phylogenetic diversity, complementarity, and endemism for conservation assessment. Conservation Biology, 18, 255-261.

Favre A, Päckert M, Pauls SU, Jähnig SC, Uhl D, Michalak I, Muellner-Riehl AN (2015) The role of the uplift of the Qinghai-Tibetan Plateau for the evolution of Tibetan biotas. Biological Reviews, 90, 236-253.

Feng G, Zhang JL, Pei NC, Rao MD, Mi XC, Ren HB, Ma KP (2012) Comparison of phylobetadiversity indices based on community data from Gutianshan Forest Plot. Chinese Science Bulletin, 57, 623-630.

Forest F, Grenyer R, Rouget M, Davies TJ, Cowling RM, Faith DP, Balmford A, Manning JC, Procheş Ş, van der Bank M, Reeves G, Hedderson TAJ, Savolainen V (2007) Preserving the evolutionary potential of floras in biodiversity hotspots. Nature, 445, 757-760.

Ge XJ (2015) Application of DNA barcoding in phylofloristics study. Biodiversity Science, 23, 295-296. (in Chinese) [葛 学军 (2015) DNA条形码在植物系统发育区系学研究中 的应用. 生物多样性, 23, 295-296.]

González-Caro S, Umaña MN, Álvarez E, Stevenson PR, Swenson NG (2014) Phylogenetic alpha and beta diversity in tropical tree assemblages along regional-scale environmental gradients in northwest South America. Journal of Plant Ecology, 7, 145-153.

Lancaster LT, Kay KM (2013) Origin and diversification of the California flora: re-examing classic hypotheses with molecular phylogenies. Evolution, 67, 1041-1054.

Lavergne S, Hampe A, Arroyo J (2013) In and out of Africa: How did the Strait of Gibraltar affect plant species migration and local diversification? Journal of Biogeography, 40, 24-36.

Li R, Kraft NJB, Yang J, Wang Y (2015) A phylogenetically informed delineation of floristic regions within a biodiversity hotspot in Yunnan, China. Scientific Reports, 5, 9396.

Linder HP, Hardy CR, Rutschmann F (2005) Taxon sampling effects in molecular clock dating: an example from the African Restionaceae. Molecular Phylogenetics and Evolution, 35, 569-582.

Linder HP (2008) Plant species radiations: where, when, why? Philosophical Transactions of the Royal Society of London B: Biological Sciences, 363, 3097-3105.

Lu LM, Sun M, Zhang JB, Li HL, Lin L, Yang T, Chen M, Chen ZD (2014) Tree of life and its applications. Biodiversity Science, 22, 3-20. (in Chinese with English abstract) [鲁丽敏, 孙苗, 张景博, 李洪雷, 林立, 杨拓, 陈闽, 陈 之端 (2014) 生命之树及其应用. 生物多样性, 22, 3-20.]

Milne RI (2006) Northern hemisphere plant disjunctions: a window on tertiary land bridges and climate change? Annals of Botany, 98, 465-472.

Mishler BD, Knerr N, González-Orozco CE, Thornhill AH, Laffan SW, Miller JT (2014) Phylogenetic measures of biodiversity and neo- and paleo-endemism in Australian Acacia. Nature Communications, 5, 4473.

Monnet AC, Jiguet F, Meynard CN, Mouillot D, Mouquet N, Thuiller W, Devictor V (2014) Asynchrony of taxonomic, functional and phylogenetic diversity in birds. Global Ecol- 
ogy and Biogeography, 23, 780-788.

Pillon Y (2012) Time and tempo of diversification in the flora of New Caledonia. Botanical Journal of the Linnean Society, 170, 288-298.

Qian H, Zhang J (2015) Are phylogenies derived from family-level supertrees robust for studies on macroecological patterns along environmental gradients? Journal of Systematics and Evolution, 54, 29-36.

Rosauer D, Laffan SW, Crisp MD, Donnellan SC, Cook LG (2009) Phylogenetic endemism: a new approach for identifying geographical concentrations of evolutionary history. Molecular Ecology, 18, 4061-4072.

Swenson NG, Umaña MN (2014) Phylofloristics: an example from the Lesser Antilles. Journal of Plant Ecology, 7, $166-175$.

Tsirogiannis C, Sandel B (2014) Computing the skewness of the phylogenetic mean pairwise distance in linear time. Algorithms for Molecular Biology, 9, 15.

Warren BH, Bakker FT, Bellstedt DU, Bytebier B, Claßen-Bockhoff R, Dreyer LL, Edwards D, Forest F, Gal- ley C, Hardy CR, Linder HP, Muasya AM, Mummenhoff K, Oberlander KC, Quint M, Richardson JE, Savolainen V, Schrire BD, van der Niet T, Verboom GA, Yesson C, Hawkins JA (2011) Consistent phenological shifts in the making of a biodiversity hotspot: the Cape flora. BMC Evolutionary Biology, 11, 39.

Webb CO, Ackerly DD, McPeek MA, Donoghue MJ (2002) Phylogenies and community ecology. Annual Review of Ecology and Systematics, 33, 475-505.

Weigelt P, Kissling WD, Kisel Y, Fritz SA, Karger DN, Kessler M, Lehtonen S, Svenning JC, Kreft H (2015) Global patterns and drivers of phylogenetic structure in island floras. Scientific Reports, 5, 12213.

Whittaker RH (1960) Vegetation of the Siskiyou Mountains, Oregon and California. Ecological Monographs, 30, 279-338.

Wu ZY, Sun H, Zhou ZK, Li DZ, Peng H (2010) Floristics of Seed Plants from China. Science Press, Beijing. (in Chinese) [吴征镒，孙航，周浙昆，李德铢，彭华 (2010) 中国种子 植物区系地理. 科学出版社, 北京.] 